OPEN ACCESS

Edited by:

Shimon Rosenheck, Meir Medical Center, Israel

Reviewed by: Benjamin Berte,

Klinik Im Park, Zurich Javier Eduardo Banchs, Baylor Scott and White Health,

United States Marco Proietti,

Birmingham University, United Kingdom

${ }^{*}$ Correspondence:

Ciro Indolfi indolfi@unicz.it

Specialty section: This article was submitted to Cardiac Rhythmology,

a section of the journal Frontiers in Cardiovascular Medicine

Received: 27 April 2017 Accepted: 08 December 2017 Published: 21 December 2017

Citation:

Santarpia G, De Rosa S, Sabatino J, Curcio $A$ and Indolfi C (2017) Should We Maintain Anticoagulation after Successful Radiofrequency Catheter Ablation of Atrial Fibrillation? The Need for a Randomized Study. Front. Cardiovasc. Med. 4:85. doi: 10.3389/fcvm.2017.00085

\section{Should We Maintain Anticoagulation after Successful Radiofrequency Catheter Ablation of Atrial Fibrillation? The Need for a Randomized Study}

\author{
Giuseppe Santarpia', Salvatore De Rosa', Jolanda Sabatino', Antonio Curcio' \\ and Ciro Indolfi ${ }^{1,2 *}$ \\ 'Division of Cardiology, Department of Medical and Surgical Sciences, Magna Græcia University, Catanzaro, Italy, \\ ${ }^{2}$ URT-CNR, Department of Medicine, Consiglio Nazionale delle Ricerche, Catanzaro, Italy
}

Background: Atrial fibrillation (AF) is associated with a high risk of thromboembolic stroke and oral anticoagulation therapy (OAT) is able to reduce the rate of ischemic events. Nevertheless, the actual benefit of prolonged OAT after successful radiofrequency catheter ablation (RFCA) is not clear yet.

Methods: Scientific investigations were assumed suitable if they assessed the clinical significance of the use of anticoagulation versus no anticoagulation in AF patients undergoing successful RFCA. The odds ratio (OR) with 95\% confidence interval (Cl) was used as the study summary measure.

Results: At meta-analysis, the rate of total thromboembolic events was not significantly different between the groups (OR 1.83, 95\% Cl 0.69-4.88; $p=0.221$ ), while a lower incidence of total bleeding events in patients not treated with OAT was found (OR 6.5, 95\% Cl 1.93-21.86; $p=0.002)$.

Conclusion: This meta-analysis raises doubts about the net clinical benefit (NCB) of a long-term prophylactic OAT in patients with AF underwent to successful RFCA. In fact, despite similar rate of thromboembolic events, the apparent increase in bleeding risk suggests caution in prolonging OAT after RFCA. However, the lack of prospective randomized studies does not allow a comprehensive appraisal of this issue. Thus, we propose the design of a novel prospective randomized trial to evaluate the NCB of prolonged OAT after successful RFCA of AF.

Keywords: anticoagulation, radiofrequency catheter ablation, atrial fibrillation, thromboembolic risk, bleeding risk

\section{BACKGROUND}

Atrial fibrillation (AF) is associated with a higher rate of cerebrovascular ischemic accidents (1). Hence, oral anticoagulation represents a cornerstone in the clinical management of AF patients to reduce the risk of thromboembolic events (2). In fact, oral anticoagulation therapy (OAT) was

\footnotetext{
Abbreviations: AF, atrial fibrillation; RFCA, radiofrequency catheter ablation; $\mathrm{CI}$, confidence interval; OAT, oral anticoagulation therapy; OR, odds ratio; TIA, transient ischemic attack; SE, systemic embolism; ECG, electrocardiogram; NOACs, nonvitamin $\mathrm{K}$ antagonist oral anticoagulants; NBC, net clinical benefit.
} 
able to achieve a $60 \%$ relative risk reduction of ischemic stroke, compared to placebo (3). For this reason, clinical guidelines for the management of AF suggest the use of OAT in all AF patients with high thromboembolic risk, with the use of percutaneous left atrial appendage occlusion being recommended in patients with clear contra-indications for OAT (4-6). At the same time, radiofrequency catheter ablation (RFCA) seems to be very effective for the treatment of AF, showing a success rate ranging from 79.7 to $88.6 \%$ for paroxysmal AF and from 66.1 to $80 \%$ for the persistent form (7). Although the indication for anticoagulation therapy in AF patients is based on their thromboembolic risk (8-11), it is not clear what the correct behavior regarding anticoagulation management in $\mathrm{AF}$ patients undergoing a successful RFCA should be. Current guidelines recommend life-long extension of OAT even after successful RFCA in case of high thromboembolic risk, while no clear recommendations are provided for patients at low thromboembolic risk (4-6). In fact, the lack of randomized trials testing long-term safety and efficacy of OAT in this specific population makes clinicians unsure on their actual usefulness in AF patients after successful RFCA. In this setting, we performed a critical revision of available clinical data on the advantage of anticoagulation versus no anticoagulation in AF patients after successful RFCA, adopting a meta-analytic approach, to integrate the conclusions of all eligible academic works with the following definite objectives: (1) evaluate safety and efficacy of anticoagulation versus non-use of anticoagulation in AF patients undergoing successful RFCA and (2) highlight the current knowledge gaps and design a randomized trial to test safety and efficacy of anticoagulation in AF patients undergoing successful RFCA, without selection bias.

\section{METHODS}

\section{Search Strategy and Study Selection}

A comprehensive literature search was performed in November 2016, using PubMed and Google Scholar electronic databases, for all articles comparing OAT to no oral anticoagulation therapy (non-OAT), published in the English language in peerreviewed journals. We excluded case reports, review articles, expert opinions, and letters to the editor. The search was performed, with no limit to the year of publication, using the following keywords: "atrial fibrillation," "anticoagulation," and "radiofrequency catheter ablation." All items were screened by two researchers for eligibility, independently. To minimize the risk of overseeing relevant studies, also references of selected articles were screened, as previously described (12). All selected studies were entirely checked and classified to exclude duplicity of data. Screened studies were included if they: (a) compared the clinical outcome with anticoagulation versus no anticoagulation in AF patients after successful RFCA; (b) reported numerical outcome data [stroke, transient ischemic attack (TIA) or systemic embolism (SE), bleedings]. Reasons for exclusion were: duplicate publication, the above listed endpoint were not reported. Study quality assessment was performed as previously described and according to the PRISMA statement $(12,13)$.

\section{Data Abstraction and Quality Assessment}

The titles, abstracts, and selected full texts generated from the literature search were independently screened by two authors. Data from the studies that met all inclusion criteria were manually extracted and entered into a standard extraction table. All selected articles were reviewed to extract all relevant data: publication year, study origin, number of patients included, type of study design, outcome data reported, key baseline variables. Selection and data abstraction were performed as previously described (Figure 1) $(12,13)$.

\section{Statistical Analysis}

We used the odds ratio (OR) with 95\% confidence interval (CI) as the summary measure. The meta-analysis was calculated using the random-effects model (14). In addition, the Mantel-Haenszel method (fixed effect model) was used alternatively, if required (15). Meta-analysis results were displayed using Forest plots, as described elsewhere (16). Heterogeneity was evaluated by means of the Cochrane Q test ( $p<0.10$ considered significant). $I^{2}$ values were also calculated, with a pre-specified $I^{2}$ threshold of $20 \%$. The random-effects model was used preferentially, where appropriate (17). Funnel plots were used to assess the eventual impact of small study effects (Figure S1 in Supplementary Material). Analyses were performed using Excel spreadsheets and OpenMetaAnalyst-0.1.

\section{RESULTS}

\section{Study Characteristics}

Database search produced 41 entries from PubMed and 59 from Google Scholar. In total, 59 studies were available after removal of duplicates. Of these, 41 studies were excluded according to the pre-specified criteria. Finally, nine studies were selected for meta-analysis (18-26). The stepwise selection process is drawn in Figure 1, while details of the selected studies are displayed in Table 1. Of all selected studies, five are single-center retrospective analyses (19-23) and four are multi-center retrospective, non-randomized, observational studies $(18,24-26)$ evaluating the safety and efficacy of oral anticoagulation during the follow-up, after a successful RFCA of AF. Quality assessment and risk of bias of the studies included in the analysis are shown in Table S1 in Supplementary Material. Briefly, no blinding was used in any of the studies included. Foremost, an evident selection bias emerges from the bias assessment. In fact, baseline thromboembolic and bleeding risk profiles were not balanced between the study arms for most of the studies included in the analysis and heterogeneously reported. Information on baseline $\mathrm{CHADS}_{2}$ or the $\mathrm{CHA}_{2} \mathrm{DS}_{2}$-VASc scores are reported in Table $\mathbf{1}$, while events recorded in each study included in the meta-analysis are displayed in Table 2; Table 3 summarizes endpoint definitions of the included studies. Longterm anticoagulation was reintroduced after the RFCA and kept for 3-12 months; it was represented by adjusted-dose warfarin in eight studies and either by warfarin or by non-vitamin K antagonist oral anticoagulants (NOACs) in the remaining study (22).

\section{Clinical Events}

A total of nine studies were selected for the meta-analysis, including 11,520 patients $(5,324$ treated with prolonged 

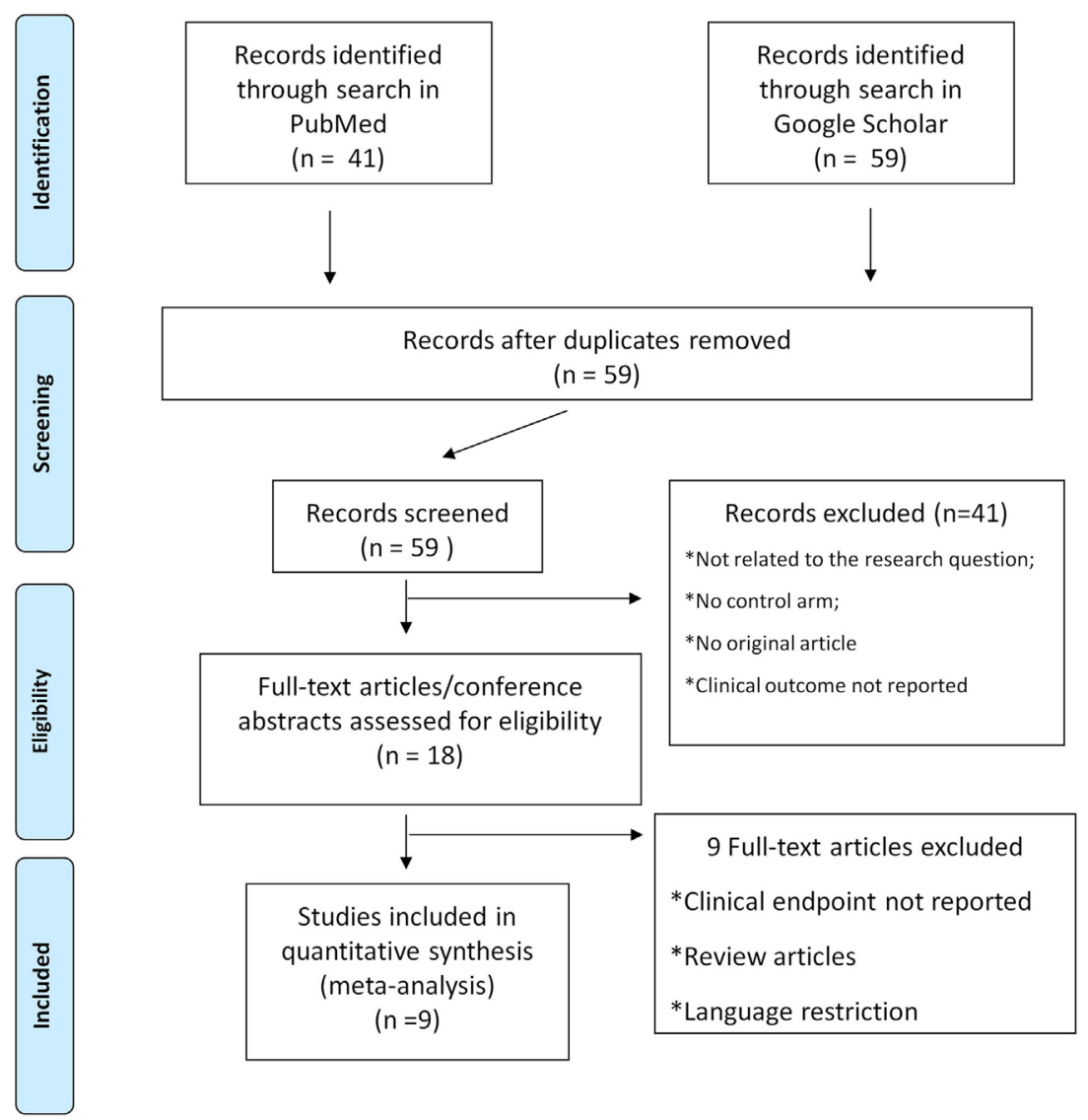

FIGURE 1 | Study selection flow chart. Selection and data abstraction process, performed according to the PRISMA statement.

TABLE 1 | Baseline patients' risk across the studies.

\begin{tabular}{|c|c|c|c|c|c|}
\hline Study & Nationality & Study subgroup & $N$ & Thromboembolic risk score & Therapy \\
\hline \multirow{2}{*}{ Bunch et al. (19) } & \multirow{2}{*}{ USA } & Oral anticoagulation therapy (OAT) & 507 & $\mathrm{CHADS}_{2}$ score $\geq 2 ; 54.8 \%$ & Warfarin (INR 2-3) \\
\hline & & Non-OAT & 123 & $\mathrm{CHADS}_{2}$ score $\geq 2 ; 0$ & ASA \\
\hline \multirow[t]{2}{*}{ Karasoy et al. (24) } & \multirow[t]{2}{*}{ Denmark } & OAT & 2476 & \multirow[t]{2}{*}{$\mathrm{CHA}_{2} \mathrm{DS}_{2}$-VASc score $\geq 2 ; 37.2 \%$} & Warfarin (INR 2-3) \\
\hline & & Non-OAT & 1574 & & None \\
\hline \multirow[t]{2}{*}{ Oral et al. (28) } & \multirow[t]{2}{*}{ USA } & OAT & 357 & - & Warfarin (INR 2-3) \\
\hline & & Non-OAT & 398 & - & None \\
\hline \multirow{2}{*}{ Saad et al. (21) } & \multirow[t]{2}{*}{ USA-Brazil } & OAT & 22 & $\mathrm{CHADS}_{2}$ score $\geq 2 ; 71 \%$ & Warfarin (INR 2-3) \\
\hline & & Non-OAT & 293 & & ASA/None \\
\hline \multirow[t]{2}{*}{ Themistoclakis et al. (25) } & \multirow[t]{2}{*}{ USA-Italy-France } & OAT & 663 & $\mathrm{CHADS}_{2}$ score $\geq 2 ; 37 \%$ & Warfarin (INR 2-3) \\
\hline & & Non-OAT & 2692 & $\mathrm{CHADS}_{2}$ score $\geq 2 ; 13 \%$ & ASA \\
\hline \multirow[t]{2}{*}{ Uhm et al. (18) } & \multirow[t]{2}{*}{ Korea } & OAT & 312 & $\mathrm{CHA}_{2} \mathrm{DS}_{2}$-VASc score $\geq 2 ; 44 \%$ & Warfarin (INR 2-3) \\
\hline & & Non-OAT & 296 & $\mathrm{CHA}_{2} \mathrm{DS}_{2}$-VASc score $\geq 2 ; 41 \%$ & ASA \\
\hline \multirow[t]{2}{*}{ Winkle et al. (22) } & \multirow[t]{2}{*}{ USA } & OAT & 48 & \multirow[t]{2}{*}{$\mathrm{CHADS}_{2}$ score $\geq 2 ; 100 \%$} & Warfarin(INR 2-3)/NOACs \\
\hline & & Non-OAT & 60 & & ASA/None \\
\hline \multirow[t]{2}{*}{ Yagishita et al. (23) } & \multirow[t]{2}{*}{ Japan } & OAT & 124 & \multirow[t]{2}{*}{$\mathrm{CHADS}_{2}$ score $\geq 2 ; 16 \%$} & Warfarin (INR 2-3) \\
\hline & & Non-OAT & 400 & & None \\
\hline \multirow[t]{2}{*}{ Själander et al. (26) } & \multirow[t]{2}{*}{ Sweden } & OAT & 815 & \multirow[t]{2}{*}{$\mathrm{CHADS}_{2}$ score $\geq 2 ; 44 \%$} & Warfarin (INR 2-3) \\
\hline & & Non-OAT & 360 & & None \\
\hline
\end{tabular}

anticoagulation and 6,196 treated without OAT). Altogether, 102 embolic events (58 in the OAT arm, 44 in the non-OAT arm) and 126 bleedings ( 99 in the OAT arm, 27 in the non-OAT arm) were captured.

\section{Stroke and Thromboembolism}

At meta-analysis, no significant difference was found in the incidence of thromboembolic events between the groups (OR 1.83 , 95\% CI $0.69-4.88 ; p=0.221$ ) (Figure 2). Of note, the 
TABLE 2 | Events' list for each study included in the meta-analysis.

\begin{tabular}{|c|c|c|c|c|c|c|}
\hline Reference & Therapy & Total embolic events & Stroke & TIA & SE & Major bleeding \\
\hline \multirow{2}{*}{ Bunch et al. (19) } & Warfarin (INR 2-3) & 5 & 4 & 0 & 1 & 2 \\
\hline & ASA & 0 & 0 & 0 & 0 & 0 \\
\hline \multirow[t]{2}{*}{ Karasoy et al. (24) } & Warfarin (INR 2-3) & 36 & - & - & 36 & 63 \\
\hline & None & 35 & - & - & 35 & 24 \\
\hline \multirow[t]{2}{*}{ Oral et al. (28) } & Warfarin (INR 2-3) & 2 & 1 & - & 1 & 2 \\
\hline & None & 0 & 0 & - & 0 & 0 \\
\hline \multirow[t]{2}{*}{ Saad et al. (21) } & Warfarin (INR 2-3) & - & - & - & - & 3 \\
\hline & ASA/None & - & - & - & - & 0 \\
\hline \multirow[t]{2}{*}{ Themistoclakis et al. (25) } & Warfarin (INR 2-3) & 3 & 3 & - & - & 13 \\
\hline & ASA & 2 & 2 & - & - & 1 \\
\hline \multirow[t]{2}{*}{ Uhm et al. (18) } & Warfarin (INR 2-3) & 3 & 1 & 2 & - & 2 \\
\hline & ASA & 1 & 1 & 0 & - & 2 \\
\hline \multirow[t]{2}{*}{ Winkle et al. (22) } & Warfarin (INR 2-3)/NOACs & 1 & 0 & 0 & 1 & 9 \\
\hline & ASA/None & 0 & 0 & 0 & 0 & 0 \\
\hline \multirow[t]{2}{*}{ Yagishita et al. (23) } & Warfarin (INR 2-3) & 3 & 2 & 1 & - & 2 \\
\hline & None & 0 & 0 & 0 & - & 0 \\
\hline \multirow[t]{2}{*}{ Själander et al. (26) } & Warfarin (INR 2-3) & 5 & 5 & - & - & 3 \\
\hline & None & 6 & 6 & - & - & 0 \\
\hline
\end{tabular}

TIA, transient ischemic attack/silent cerebral ischemia; SE, systemic embolism.

TABLE 3 | Endpoints' definition for any study included in the meta-analysis.

\begin{tabular}{|c|c|c|c|}
\hline Study & Major bleeding & Stroke & Thromboembolism \\
\hline Bunch et al. (19) & Not available & Not available & Not available \\
\hline Karasoy et al. (24) & $\begin{array}{l}\text { Intracranial bleeding or bleeding from } \\
\text { respiratory, gastrointestinal, or urinary tract }\end{array}$ & Not available & $\begin{array}{l}\text { Ischemic stroke, transient ischemic attack (TIA) } \\
\text { or peripheral artery embolism }\end{array}$ \\
\hline Oral et al. (28) & Not available & Not available & Not available \\
\hline Saad et al. (21) & Not available & Not available & Not available \\
\hline Themistoclakis et al. (25) & $\begin{array}{l}\text { Intracranial or retroperitoneal bleeding. } \\
\text { Bleeding leading directly to death, or resulted } \\
\text { in hospitalization or transfusion }\end{array}$ & $\begin{array}{l}\text { The abrupt onset of focal neurological } \\
\text { deficit persisting for more than } 24 \mathrm{~h}\end{array}$ & Not available \\
\hline Uhm et al. (18) & $\begin{array}{l}\text { Any type of hemorrhage requiring blood } \\
\text { transfusion or intervention and bleeding with } \\
\text { reduction of hemoglobin levels by } \geq 4.0 \mathrm{~g} / \text { day }\end{array}$ & $\begin{array}{l}\text { Symptomatic ischemic cerebral infarction } \\
\text { with apparent brain lesion in imaging } \\
\text { studies }\end{array}$ & $\begin{array}{l}\text { Stroke, TIA, and any other systemic embolism } \\
\text { (SE) }\end{array}$ \\
\hline Winkle et al. (22) & Not available & Not available & Not available \\
\hline Yagishita et al. (23) & Not available & $\begin{array}{l}\text { The abrupt onset of focal neurological } \\
\text { deficit }\end{array}$ & Stroke, TIA, and any other SE \\
\hline Själander et al. (26) & Intracranial hemorrhage & $\begin{array}{l}\text { The abrupt onset of focal neurological } \\
\text { deficit }\end{array}$ & Not available \\
\hline
\end{tabular}

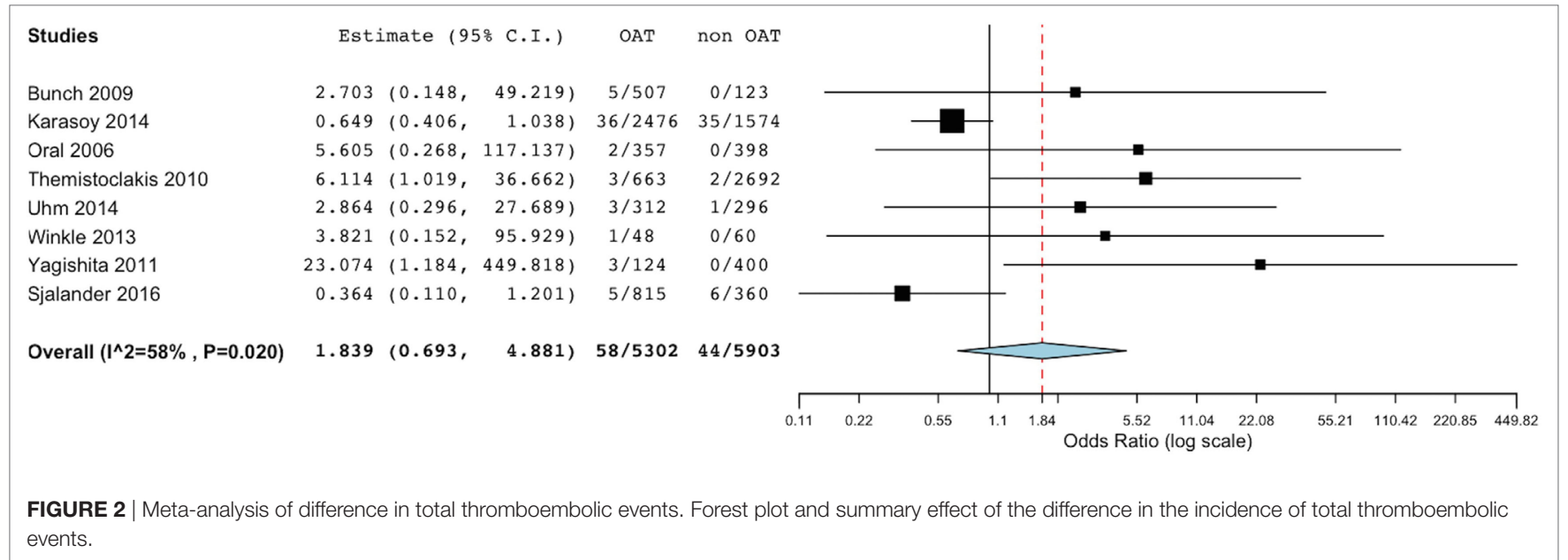


sensitivity analysis revealed consistency of this result. In fact, removal of each single study did not result in significant changes of meta-analysis results. Evaluating the summary effect on the cumulative endpoint of ischemic stroke, no significant difference was evident between OAT and non-OAT-treated arms (OR 1.87, 95\% CI 0.56-6.26; $p=0.308$ ) (Figure 3A). A smaller number of studies independently provided numerical data on the specific endpoints of TIA and SE. Summing up the available evidence from those studies, no significant difference was found (OR $2.55,95 \%$ CI $0.45-14.3 ; p=0.29$ for TIA and OR $0.97,95 \%$ CI $0.43-2.2 ; p=0.95$ for SE) (Figures 3B,C).

\section{Bleedings}

Bleeding rates were available from all included studies. Summing up the evidence from all these studies, we found a significantly lower incidence of total bleeding events in the non-OAT arm (OR 6.5, 95\% CI 1.93-21.86; $p=0.002$ ) (Figure 4). At sensitivity analysis, we found consistence of the above described results across single studies, as the overall summary effect was not significantly different after alternatively removal of single studies.

\section{DISCUSSION}

The actual benefit of anticoagulation therapy on a medium-to long-term follow-up after successful RFCA of AF is currently unclear. In fact, the incidence of thromboembolic complications during this time window is highly variable, ranging from 0.5 to $7 \%(27-32)$. This makes it difficult to assess the impact of prolonged OAT, or the optimal duration of OAT after RFCA.

\begin{tabular}{|c|c|c|c|c|}
\hline \multicolumn{5}{|l|}{$\mathbf{A}$} \\
\hline Studies & Estimate $(95$ & $5 \%$ C.I.) & $\mathrm{OAT}$ & non OAT \\
\hline Bunch 2009 & $2.208 \quad 0.118$ & $41.275)$ & $4 / 507$ & $0 / 123$ \\
\hline Oral 2006 & $3.353(0.136$ & $82.581)$ & $1 / 357$ & $0 / 398$ \\
\hline Themistoclakis 2010 & $6.114(1.019$, & $36.662)$ & $3 / 663$ & $2 / 2692$ \\
\hline Uhm 2014 & $0.949 \quad(0.059$, & $15.235)$ & $1 / 312$ & $1 / 296$ \\
\hline Winkle 2013 & $1.247(0.024$ & $64.018)$ & $0 / 48$ & $0 / 60$ \\
\hline Yagishita 2011 & $16.347(0.780$ & $342.797)$ & $2 / 124$ & $0 / 400$ \\
\hline Sjalander 2016 & $0.364 \quad(0.110$, & $1.201)$ & $5 / 815$ & $6 / 360$ \\
\hline Overall $\left(I^{\wedge} 2=42 \%, P=0.109\right)$ & $1.873(0.560$ & $6.261)$ & $16 / 2826$ & $9 / 43$ \\
\hline
\end{tabular}

Studies

Bunch 2009

Uhm 2014

Winkle 2013

Yagishita 2011

Overall $\left(I^{\wedge} 2=0 \%, P=0.506\right)$
Estimate (95\% C.I.) OAT non-OAT

$0.243(0.005,12.325) \quad 0 / 507$

$4.775(0.228,99.866) 2 / 312$

$1.247(0.024,64.018) 0 / 48$

$9.729(0.394,240.337) 1 / 124$

$2.546(0.452,14.334) 3 / 991$

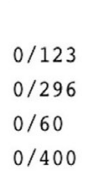

$0 / 879$

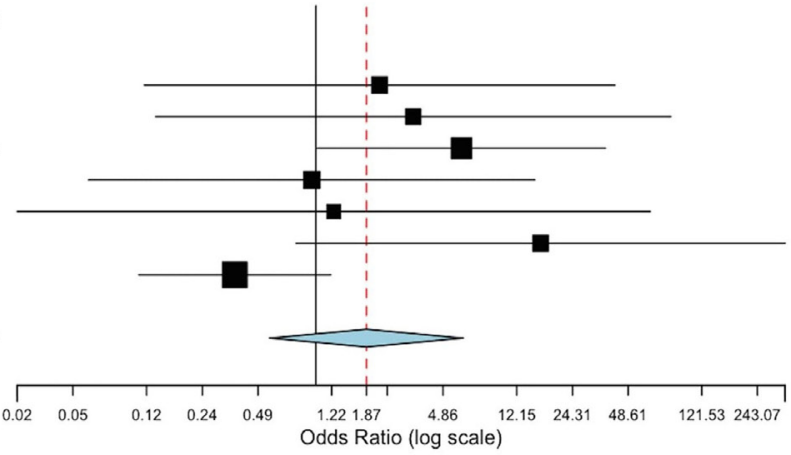

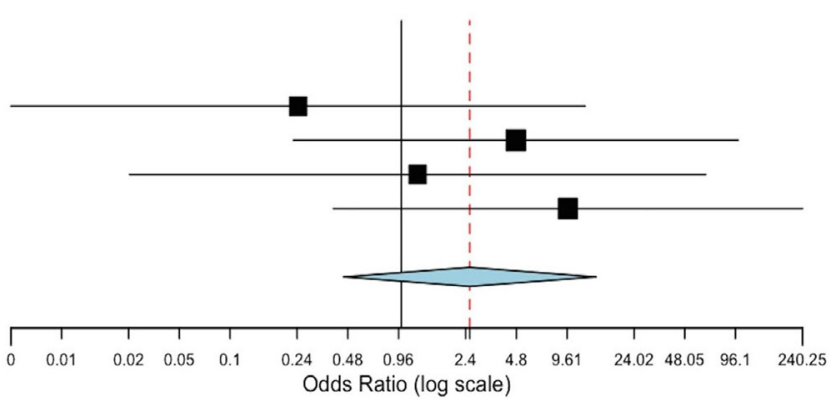

C

Studies

Bunch 2009

Karasoy 2014

Oral 2006

Winkle 2013

Yagishita 2011

Overall $\left(I^{\wedge} 2=11 \%, P=0.344\right)$

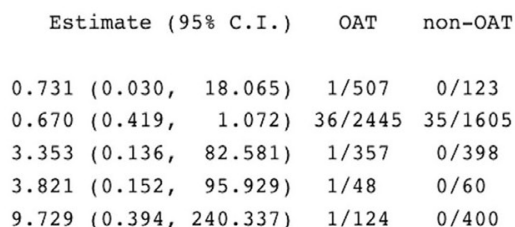

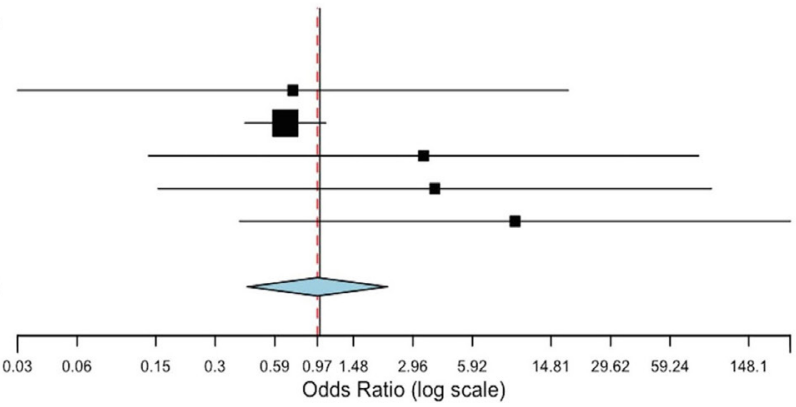

FIGURE 3 | Meta-analysis of difference in stroke, transient ischemic attack (TIA) and systemic embolic events. (A) Forest plot and summary effect of the difference in the incidence of stroke. (B) Forest plot and summary effect of the difference in the incidence of TIA. (C) Forest plot and summary effect of the difference in the incidence of systemic embolism. 


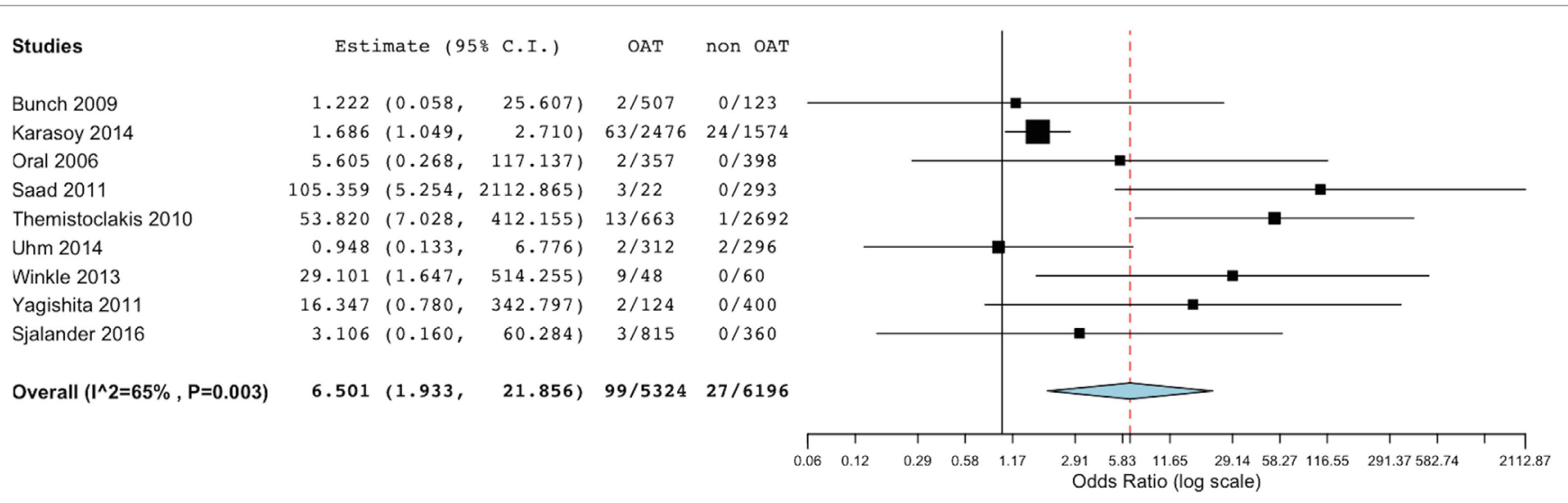

FIGURE 4 | Meta-analysis of difference in total bleeding events. Forest plot and summary effect of the difference in the incidence of total bleedings.

None of the currently available studies on this topic is randomized and they all suffer from an obvious selection bias. In fact, baseline thromboembolic risk is unbalanced in several of the selected studies. As Oral et al. reported, thromboembolic events are generally more frequent within the 30-days time window after RFCA (20). The underlying reasons are probably multifactorial, but the almost exclusively use of warfarin in these studies may have played a role. Hence, a larger use of NOACs could improve thromboembolic prevention in the early phase. The present study is the only meta-analysis comparing prolonged OAT versus non-OAT after successful RFCA of AF. Our results suggest caution with use of prolonged OAT after successful RFCA of AF. In fact, we found a significantly lower incidence of total bleeding events in the non-OAT arm, despite no significant change in the rate of total thromboembolic events. However, given the non-randomized design of available studies, and the evident selection bias, it is difficult to discern the variations associated with OAT treatment to those related to the different baseline risk.

\section{LIMITATIONS OF THE PRESENT META- ANALYSIS}

Since all studies available are non-randomized retrospective trials, we cannot exclude a sampling bias. In addition, blinded analysis or central endpoint classification and adjudication were not performed in all studies included in this meta-analysis. Accordingly, the studies were not balanced between the treatment arms. Furthermore, baseline clinical risk data were heterogeneously reported across the studies included, which made impossible to risk-stratify or to evaluate the impact of any score in meta-regression analyses to assess the impact of the observed imbalance between the treatment arms on study outcomes. These limitations are also reflected in the large CI of the effect size for most studies. Finally, bleeding events were differently classified and heterogeneously reported across the studies included in the present meta-analysis.

\section{PROPOSAL FOR A NOVEL RANDOMIZED STUDY}

In light of the significantly increased bleeding risk associated to prolonged OAT after successful RFCA of AF in the present analysis, as well as the inconclusive results on prevention of thromboembolic events from the non-randomized studies available so far, a randomized study should be designed to explore the actual benefits and risks of anticoagulation therapy in AF patients undergone to successful RFCA, as no conclusive answer to this question was found, yet. In fact, while on one hand previous and current risk stratification strategies $\left(\mathrm{CHADS}_{2}, \mathrm{CHA}_{2} \mathrm{DS}_{2}\right.$-VASc score) seem to predict the stroke risk in AF patients at least in part independently of the presence of AF, Bunch and colleagues clearly showed that AF ablation is able to reduce the stroke risk, independently of baseline risk score (33). For this reason, eligible patients should be randomized in a 1:1 ratio to either no further anticoagulation or prolonged OAT 3 months after successful RFCA. Criteria to define a successful RFCA procedure should be lack of palpitations and absence of arrhythmia at the 24-h Holter electrocardiogram (ECG) performed 3 months after the procedure. All patients with successful RFCA, should undergo a thromboembolic risk stratification to be classified in low, intermediate or high thromboembolic risk classes using the $\mathrm{CHA}_{2} \mathrm{DS}_{2}$-VASc score, the most widely used and well-validated score for the assessment of thromboembolic risk in AF. Patients with $\mathrm{CHA}_{2} \mathrm{DS}_{2}$-VASc $<1$, will be classified as low thromboembolic risk patients, while those with $\mathrm{CHA}_{2} \mathrm{DS}_{2}$-VASc $\geq 1$ will be labeled as intermediate thromboembolic risk patients and lastly, those with $\mathrm{CHA}_{2} \mathrm{DS}_{2}$-VASc $>2$ will be included in the high thromboembolic risk patients' category (Figure 5; Box 1). Bleeding risk will be estimated by means the ORBIT score (34), a novel and promising risk score that was specifically validated for AF patients. Eligible patients will be classified in low, intermediate, and high bleeding risk as follows: patients with ORBIT score $\leq 2$, will be classified as low bleeding risk patients, while those with ORBIT score $=3$ will be labeled as 


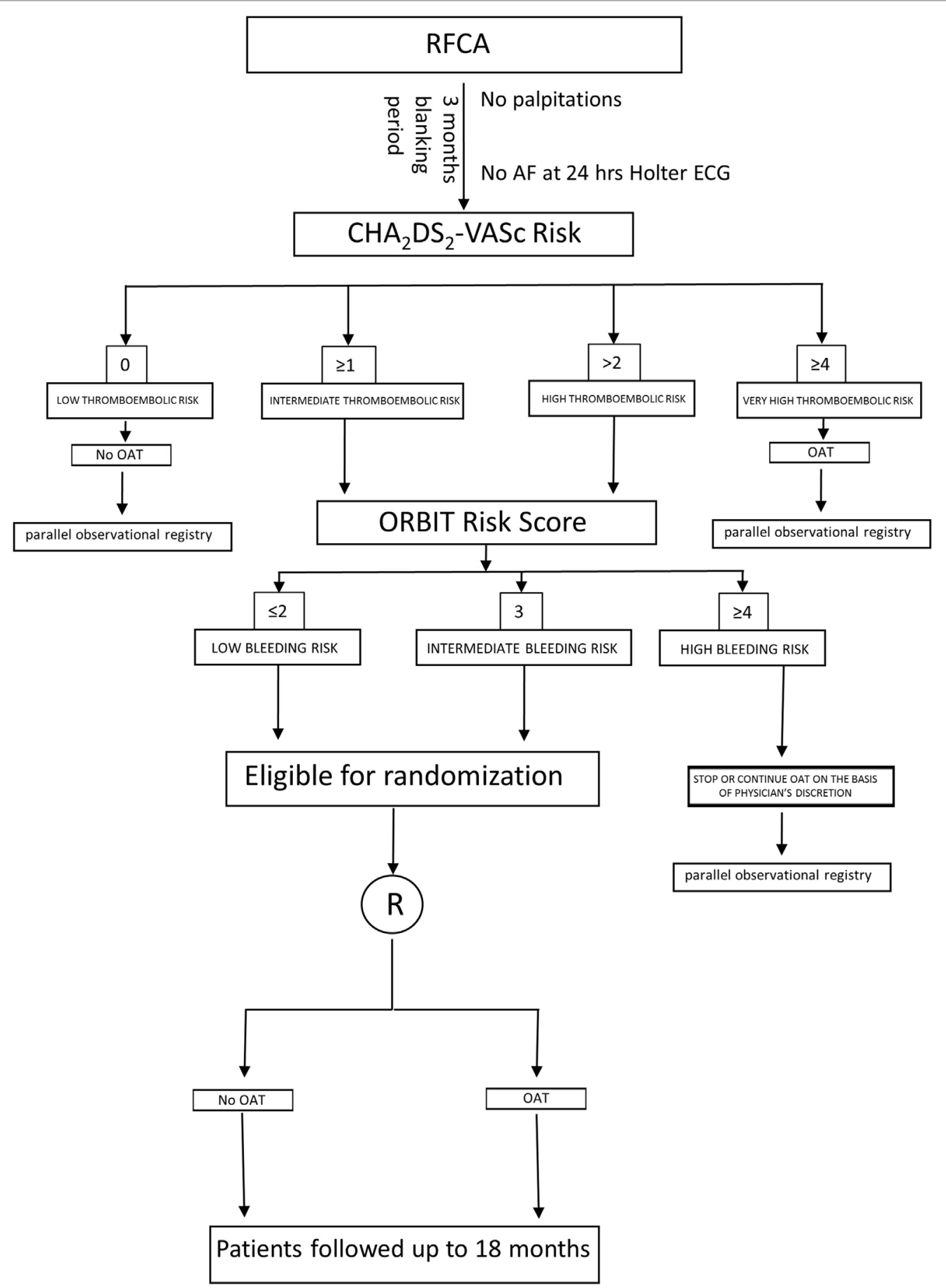

Permanent AF refractory to electrical cardioversion

LA size $>55 \mathrm{~mm}$ as measured by echocardiogram

Clinical coronary artery stenosis $>75 \%$ of luminal diameter

Severe mitral valve disease

Prior RFCA of AF

Recurrence of $A F$ after blanking period

High bleeding risk (ORBIT score $\geq 4$ ) 


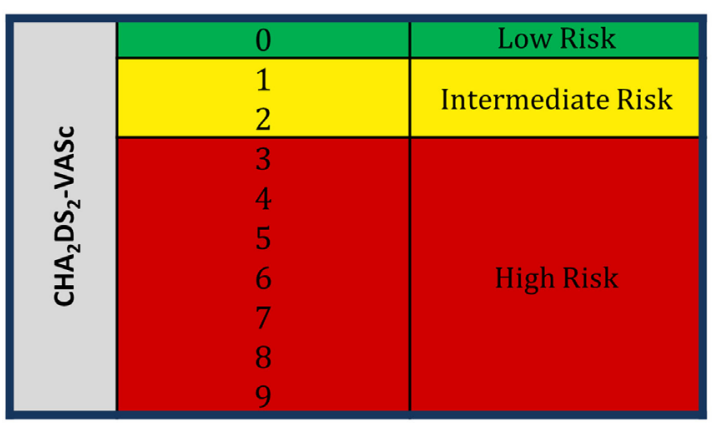

Box 1. Thromboembolic risk on the basis of $\mathrm{CHA}_{2} \mathrm{DS}_{2}$-VASc score

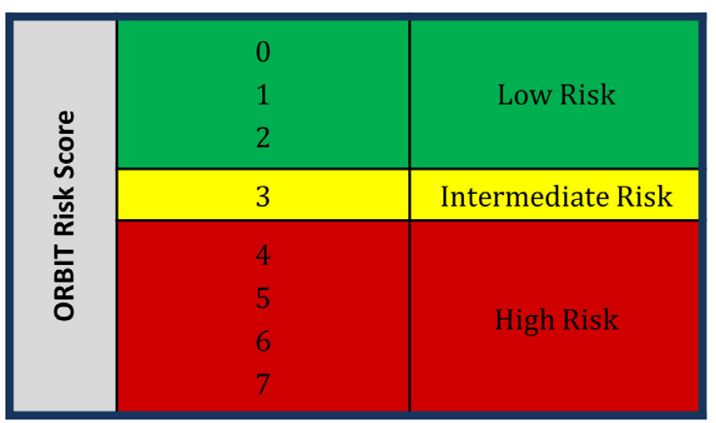

Box 2. Bleeding risk on the basis of ORBIT score

FIGURE 5 | Study design flowchart. Schematic representation of patients' selection and randomization.

\section{Study Timeline}

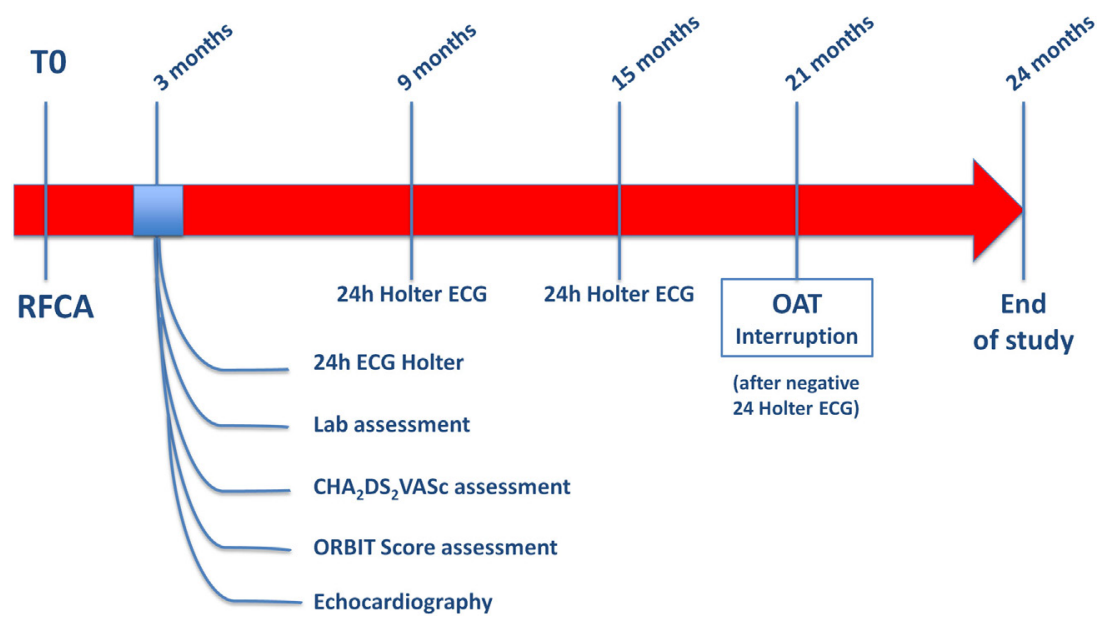

FIGURE 6 | Study timeline. Study related procedures in a timeline.

intermediate bleeding risk patients; finally, those with ORBIT score $\geq 4$ will be included in the high bleeding risk patients' category (Figure 5; Box 2). As reported in the study flowchart (Figure 5), patients with intermediate to high thromboembolic risk, and low to intermediate bleeding risk will be eligible for randomization to prolonged anticoagulation versus no anticoagulation therapy in 1:1 ratio. We propose to perform randomization 3 months after RFCA, to avoid inclusion of patients with early recurrence of AF. Nevertheless, presence of normal sinus rhythm at $24 \mathrm{~h}$ Holter ECG in asymptomatic patients does not completely exclude the possibility of AF recurrence over the mid-to long-term period. However, this reflects the situation that clinicians usually face in daily practice. In fact, a decision to prolong the OAT has to be taken at that time point, with no crystal ball to look into. Hence, the primary analysis should be performed on an "intention to treat" basis, to provide clinicians with results that should be reflecting as much as possible a real-life clinical scenario. An "as treated" analysis will additionally be performed to account for patients that will develop AF recurrence during the study period. Nevertheless, every effort should be made to detect asymptomatic AF events within the study. For this reason, we plan to repeat 24-h Holter ECG at months 9, 15, and 21. The study timeline is depicted in Figure 6. In addition, to increase the chance to detect asymptomatic AF events during the study, a subgroup of patients will be invited to participate to a sub-study (based on their age and level of confidence with mobile devices). Patients agreeing to enter the sub-study will be provided with a smartphone application to detect AF through measurement and analysis of finger-tip photopletismography. All patients will be observed for a follow-up period of 18 months after which they will enter a 3-months observational period (no OAT in both arms). Patients at low thromboembolic risk, as well as patients with very high thromboembolic risk $\left(\mathrm{CHA}_{2} \mathrm{DS}_{2}\right.$-VASc $\left.\geq 4\right)$ will, respectively, qualify for no anticoagulation or to anticoagulation therapy at physician discretion and they will be included in a parallel observational registry. Patients with recurrence of palpitations or documented AF during the 3 months after RFCA as well as 
patient with AF diagnosed by smart monitoring or 24-h Holter ECG planned during follow-up time, will qualify for OAT, irrespective of the arm they will be randomized to. Patients at high bleeding risk will be excluded. The patients' selection and study flowchart is simplified in Figure 5. The primary endpoint will be net clinical benefit (NCB) defined as a hierarchical composite of ischemic stroke, major thromboembolic events and major bleedings. Major thromboembolic events will include systemic and pulmonary embolism, while major bleeding will be defined accordingly to the BARC bleeding classification (types 2-5) $(35,36)$. Secondary endpoints will be: stroke (ischemic), systemic thromboembolism, major bleedings, and non-major bleedings. Based on currently available data on the incidence of thromboembolic and bleeding events in similar populations, we estimate that 970 patients will be required to reach an $80 \%$ power for detection of a $50 \%$ decrease of the primary endpoint at a 5\% significance level. However, the sample size will be enlarged to 1,010 patients ( 505 per arm) to account for a $2 \%$ crossover rate.

\section{CONCLUSION}

Oral anticoagulation therapy is currently recommended by clinical practice guidelines for thromboembolic prophylaxis of AF patients at high thromboembolic risk. However, its actual benefits for long-term prophylaxis of AF patients after successful RFCA are unclear. Despite the beyond adduced possible drawbacks, the current meta-analysis, the broadest and most complete applicable up to now, indicates that long-term anticoagulation therapy is not free from risk of potential serious complications. In fact, a prolonged anticoagulation therapy in patients with AF after successful RFCA is associated to an increase of major bleeding events with no evidence of prevention of total thromboembolic complications. In this context, we propose the draft of a prospective randomized study to assess the best postprocedural management of AF patients treated with successful RFCA with the aim of assessing the actual NCB of a prolonged oral anticoagulation in these patients.

\section{AUTHOR CONTRIBUTIONS}

GS, SR, and JS conceived the study. JS performed all analyses. GS, SR, and JS interpreted analyses results and drafted the manuscript. AC and CI made critical revision of the manuscript. CI gave the final approval.

\section{ACKNOWLEDGMENTS}

The authors are thankful to Dr. Jan Steffel, University Hospital Zurich, for critical proof reading of the manuscript.

\section{SUPPLEMENTARY MATERIAL}

The Supplementary Material for this article can be found online at http://www.frontiersin.org/articles/10.3389/fcvm.2017.00085/ full\#supplementary-material.

FIGURE S1 | No apparent publication bias was evident from the funnel plots for the endpoints of thromboembolic events (A), ischemic stroke (B), transient ischemic attack (C), and total bleeding events (D). Circles represent studies. The position of each circle on the $y$-axis represents the standard error of the Log $\mathrm{OR}$, while its position on the $\mathrm{x}$-axis represents the effect size (OR).

\section{REFERENCES}

1. Lloyd-Jones D, Adams R, Carnethon M, De Simone G, Ferguson TB, Flegal K, et al. Heart disease and stroke statistics-2009 update: a report from the AHA Statistics Committee and Stroke Statistics Subcommittee. Circulation (2009) 119:480-6. doi:10.1161/CIRCULATIONAHA.108.191259

2. Ganesan AN, Chew DP, Hartshorne T, Selvanayagam JB, Aylward PE, Sanders $\mathrm{P}$, et al. The impact of atrial fibrillation type on the risk of thromboembolism, mortality, and bleeding: a systematic review and meta-analysis. Eur Heart J (2016) 37:1591-602. doi:10.1093/eurheartj/ehw007

3. Hart RG, Pearce LA, Aguilar MI. Meta-analysis: antithrombotic therapy to prevent stroke in patients who have nonvalvular atrial fibrillation. Ann Intern Med (2007) 146:857-67. doi:10.7326/0003-4819-146-12-20070619000007

4. January CT, Wann LS, Alpert JS, Calkins H, Cigarroa JE, Cleveland JC Jr, et al. 2014 AHA/ACC/HRS guideline for the management of patients with atrial fibrillation: a report of the American College of Cardiology/ American Heart Association Task Force on Practice Guidelines and the Heart Rhythm Society. J Am Coll Cardiol (2014) 64:e1-76. doi:10.1016/j. jacc.2014.03.022

5. Camm JA, Lip GYH, De Caterina R, Savelieva I, Atar D, Hohnloser SH, et al. 2012 focused update of the ESC guidelines for the management of atrial fibrillation: an update of the 2010 ESC guidelines for the management of atrial fibrillation. Eur Heart J (2012) 33:2719-47. doi:10.1093/eurheartj/ehs253

6. Kirchhof P, Benussi S, Kotecha D, Ahlsson A, Atar D, Casadei B, et al. 2016 ESC guidelines for the management of atrial fibrillation developed in collaboration with EACTS. Eur Heart J (2016) 37:2893-962. doi:10.1093/ eurheartj/ehw210

7. Cappato R, Calkins H, Chen SA, Davies W, Iesaka Y, Kalman J, et al. Updated worldwide survey on the methods, efficacy, and safety of catheter ablation for human atrial fibrillation. Circ Arrhythm Electrophysiol (2010) 3:32-8. doi:10.1161/CIRCEP.109.859116

8. Chao TF, Lin YJ, Tsao HM, Tsai CF, Lin WS, Chang SL, et al. CHADS(2) and CHA(2)DS(2)-VASc scores in the prediction of clinical outcomes in patients with atrial fibrillation after catheter ablation. JAm Coll Cardiol (2011) 58:2380-5. doi:10.1016/j.jacc.2011.08.045

9. Cullen MW, Kim S, Piccini JP Sr, Ansell JE, Fonarow GC, Hylek EM, et al. Risks and benefits of anticoagulation in atrial fibrillation: insights from the outcomes registry for better informed treatment of atrial fibrillation (ORBIT-AF) registry. Circ Cardiovasc Qual Outcomes (2013) 6:461-9. doi:10.1161/CIRCOUTCOMES.113.000127

10. Santarpia G, De Rosa S, Polimeni A, Giampà S, Micieli M, Curcio A, et al. Efficacy and safety of non-vitamin $\mathrm{K}$ antagonist oral anticoagulants versus vitamin $\mathrm{K}$ antagonist oral anticoagulants in patients undergoing radiofrequency catheter ablation of atrial fibrillation: a meta-analysis. PLoS One (2015) 10:e0126512. doi:10.1371/journal.pone.0126512

11. Santarpia G, Curcio A, Sibilio G, Indolfi C. Clinical significance of non-vitamin $\mathrm{K}$ antagonist oral anticoagulants in the management of atrial fibrillation. Circ J (2015) 79:914-23. doi:10.1253/circj.CJ-15-0319

12. De Rosa S, Caiazzo G, Torella D, Indolfi C. Intracoronary abciximab reduces death and major adverse cardiovascular events in acute coronary syndromes: a meta-analysis of clinical trials. Int J Cardiol (2013) 168:1298-305. doi:10.1016/j.ijcard.2012.12.003

13. Moher D, Liberati A, Tetzlaff J, Altman DG. The PRISMA group. Preferred reporting items for systematic reviews and meta-analysis: the PRISMA statement. PLoS Med (2009) 6:e1000097. doi:10.1371/journal.pmed.1000097 
14. DerSimonian R, Laird N. Meta-analysis in clinical trials. Control Clin Trials (1986) 7:177-88. doi:10.1016/0197-2456(86)90046-2

15. Mantel N, Haenszel W. Statistical aspects of the analysis of data from retrospective studies of disease. J Natl Cancer Inst (1959) 22:719-48. doi:10.1093/ jnci/22.4.719

16. De Rosa S, Caiazzo G, Torella D, Indolfi C. Intracoronary versus intravenous abciximab bolus administration. J Am Coll Cardiol (2014) 63:1340-1. doi:10.1016/j.jacc.2013.08.1662

17. De Rosa S, Torella D, Caiazzo G, Giampà S, Indolfi C. Left radial access for percutaneous coronary procedures: from neglected to performer? A meta-analysis of 14 studies including 7,603 procedures. Int J Cardiol (2014) 171:66-72. doi:10.1016/j.ijcard.2013.11.046

18. Uhm JS, Won H, Joung B, Nam GB, Choi KJ, Lee MH, et al. Safety and efficacy of switching anticoagulation to aspirin three months after successful radiofrequency catheter ablation of atrial fibrillation. Yonsei Med J (2014) 55:1238-45. doi:10.3349/ymj.2014.55.5.1238

19. Bunch TJ, Crandall BG, Weiss JP, May HT, Bair TL, Osborn JS, et al. Warfarin is not needed in low-risk patients following atrial fibrillation ablation procedures. J Cardiovasc Electrophysiol (2009) 20:988-93. doi:10.1111/j. 1540-8167.2009.01481

20. Oral H, Chugh A, Ozaydin M, Good E, Fortino J, Sankaran S, et al. Risk of thromboembolic events after percutaneous left atrial radiofrequency ablation of atrial fibrillation. Circulation (2006) 114:759-65. doi:10.1161/ CIRCULATIONAHA.106.641225

21. Saad EB, D'Avila A, Costa IP, Aryana A, Slater C, Costa RE, et al. Very low risk of thromboembolic events in patients undergoing successful catheter ablation of atrial fibrillation with a CHADS2 score $\leq 3$ : a long-term outcome study. Circ Arrhythm Electrophysiol (2011) 4:615-21. doi:10.1161/ CIRCEP.111.963231

22. Winkle RA, Mead RH, Engel G, Kong MH, Patrawala RA. Discontinuing anticoagulation following successful atrial fibrillation ablation in patients with prior strokes. J Interv Card Electrophysiol (2013) 38:147-53. doi:10.1007/ s10840-013-9835-1

23. Yagishita A, Takahashi Y, Takahashi A, Fujii A, Kusa S, Fujino T, et al. Incidence of late thromboembolic events after catheter ablation of atrial fibrillation. Circ J (2011) 75:2343-9. doi:10.1253/circj.CJ-11-0065

24. Karasoy D, Gislason GH, Hansen J, Johannessen A, Køber L, Hvidtfeldt M, et al. Oral anticoagulation therapy after radiofrequency ablation of atrial fibrillation and the risk of thromboembolism and serious bleeding: long-term follow-up in nationwide cohort of Denmark. Eur Heart J (2015) 36:307-14. doi:10.1093/eurheartj/ehu421

25. Themistoclakis S, Corrado A, Marchlinski FE, Jais P, Zado E, Rossillo A, et al. The risk of thromboembolism and need for oral anticoagulation after successful atrial fibrillation ablation. J Am Coll Cardiol (2010) 55:735-43. doi:10.1016/j.jacc.2009.11.039

26. Själander S, Holmqvist F, Smith JG, Platonov PG, Kesek M, Svensson PJ, et al. Assessment of use vs discontinuation of oral anticoagulation after pulmonary vein isolation in patients with atrial fibrillation. JAMA Cardiol (2017) 2:146-52. doi:10.1001/jamacardio.2016.4179

27. Pappone C, Rosanio S, Augello G, Gallus G, Vicedomini G, Mazzone P, et al. Mortality, morbidity, and quality of life after circumferential pulmonary vein ablation for atrial fibrillation: outcomes from a controlled nonrandomized long-term study. J Am Coll Cardiol (2003) 42:185-97. doi:10.1016/ S0735-1097(03)00577-1

28. Oral H, Chugh A, Good E, Sankaran S, Reich SS, Igic P, et al. A tailored approach to catheter ablation of paroxysmal atrial fibrillation. Circulation (2006) 113:1824-31. doi:10.1161/CIRCULATIONAHA.105.601898

29. Chen SA, Hsieh MH, Tai CT, Tsai CF, Prakash VS, Yu WC, et al. Initiation of atrial fibrillation by ectopic beats originating from the pulmonary veins: electrophysiological characteristics, pharmacological responses, and effects of radiofrequency ablation. Circulation (1999) 100:1879-86. doi:10.1161/01.CIR.100.18.1879

30. Haissaguerre M, Shah DC, Jais P, Hocini M, Yamane T, Deisenhofer I, et al. Electrophysiological breakthroughs from the left atrium to the pulmonary veins. Circulation (2000) 102:2463-5. doi:10.1161/01.CIR. 102.20.2463

31. Marrouche NF, Dresing T, Cole C, Bash D, Saad E, Balaban K, et al. Circular mapping and ablation of the pulmonary vein for treatment of atrial fibrillation: impact of different catheter technologies. J Am Coll Cardiol (2002) 40:464-74. doi:10.1016/S0735-1097(02)01972-1

32. Oral H, Knight BP, Ozaydin M, Chugh A, Lai SW, Scharf C, et al. Segmental ostial ablation to isolate the pulmonary veins during atrial fibrillation: feasibility and mechanistic insights. Circulation (2002) 106:1256-62. doi:10.1161/01. CIR.0000027821.55835.00

33. Bunch TJ, May HT, Bair TL, Weiss JP, Crandall BG, Osborn JS, et al. Atrial fibrillation ablation patients have long-term stroke rates similar to patients without atrial fibrillation regardless of CHADS2 score. Heart Rhythm (2013) 10:1272-7. doi:10.1016/j.hrthm.2013.07.002

34. O'Brien EC, Simon DN, Thomas LE, Hylek EM, Gersh BJ, Ansell JE, et al. The ORBIT bleeding score: a simple bedside score to assess bleeding risk in atrial fibrillation. Eur Heart J (2015) 36:3258-64. doi:10.1093/ eurheartj/ehv476

35. Mehran R, Rao SV, Bhatt DL, Gibson CM, Caixeta A, Eikelboom J, et al. Standardized bleeding definitions for cardiovascular clinical trials: a consensus report from the Bleeding Academic Research Consortium. Circulation (2011) 123:2736-47. doi:10.1161/CIRCULATIONAHA.110.009449

36. Hicks KA, Stockbridge NL, Targum SL, Temple RJ. Bleeding Academic Research Consortium consensus report: the food and drug administration perspective. Circulation (2011) 123:2664-5. doi:10.1161/CIRCULATIONAHA.111. 032433

Conflict of Interest Statement: The authors declare that the research was conducted in the absence of any commercial or financial relationships that could be construed as a potential conflict of interest.

Copyright (c) 2017 Santarpia, De Rosa, Sabatino, Curcio and Indolfi. This is an open-access article distributed under the terms of the Creative Commons Attribution License (CC BY). The use, distribution or reproduction in other forums is permitted, provided the original author(s) or licensor are credited and that the original publication in this journal is cited, in accordance with accepted academic practice. No use, distribution or reproduction is permitted which does not comply with these terms. 